\title{
SARS-CoV-2 in Semen
}

\author{
Viroj Wiwanitkit \\ Dr. D.Y. Patil University, Pune, India
}

Dear Editor,

I would like to discuss the publication "Investigation of SARS-CoV-2 in semen of patients in the acute stage of COVID-19 infection" [1]. Kayaaslan et al. [1] concluded that "although all semen samples were obtained in the acute stage of the infection when the nasopharyngeal swab test was positive, we did not detect SARS-CoV-2 in semen." In fact, there are some previous reports showing no existence of pathogen in semen samples [2,3]. Nevertheless, a recent meta-analysis still noted that there is still a requirement for caution on the possibility of COVID-19 transmission via sexual contact [4]. In fact, there is a very low possibility that semen will be the body fluid leading to disease transmission. During a sexual contact, the distance between partners is very short, and the chance of transmission by respiratory contact should be a more important consideration [5].

\section{Disclosure Statement}

There is no conflict of interest.

\section{References}

1 Kayaaslan B, Korukluoglu G, Hasanoglu I, Kalem AK, Eser F, Akinci E, et al. Investigation of SARS-CoV-2 in semen of patients in the acute stage of COVID-19 infection. Urol Int. 2020;104(9-10):678-83.

2 Pavone C, Giammanco GM, Baiamonte D, Pinelli $\mathrm{M}$, Bonura $\mathrm{C}$, Montalbano $\mathrm{M}$, et al. Italian males recovering from mild COVID-19 show no evidence of SARS-CoV-2 in semen despite prolonged nasopharyngeal swab positivity. Int J Impot Res. 2020 Sep;32(5):560-2.

3 González-Castro A, Peñasco Y, EscuderoAcha P, Cuenca E. [Isolation of SARS-CoV-2 on reproductive tissue, a possible path of transmission]. Rev Esp Salud Publica. 2020 Jul;94:e1-2. Spanish.
4 Khalili MA, Leisegang K, Majzoub A, Finelli R, Panner Selvam MK, Henkel R, et al. Male fertility and the COVID-19 pandemic: systematic review of the literature. World J Mens Health. 2020 Oct;38(4):506-20.

5 Wiwanitkit V. Atypical modes of COVID-19 transmission: how likely are they? Epidemiol Health. 2020;42:e2020059. 